This item was submitted to Loughborough's Research Repository by the author.

Items in Figshare are protected by copyright, with all rights reserved, unless otherwise indicated.

\title{
Using dynamic geometry to introduce calculus concepts: CalGeo and the case of derivative
}

PLEASE CITE THE PUBLISHED VERSION

http://dx.doi.org/10.1080/14794800801916655

PUBLISHER

Routledge (Taylor \& Francis) @ British Society for Research into Learning Mathematics

VERSION

AM (Accepted Manuscript)

LICENCE

CC BY-NC-ND 4.0

REPOSITORY RECORD

Biza, Irene, and Theodossios Zachariades. 2019. "Using Dynamic Geometry to Introduce Calculus Concepts: Calgeo and the Case of Derivative". figshare. https://hdl.handle.net/2134/11590. 
This item was submitted to Loughborough's Institutional Repository (https://dspace.lboro.ac.uk/) by the author and is made available under the following Creative Commons Licence conditions.

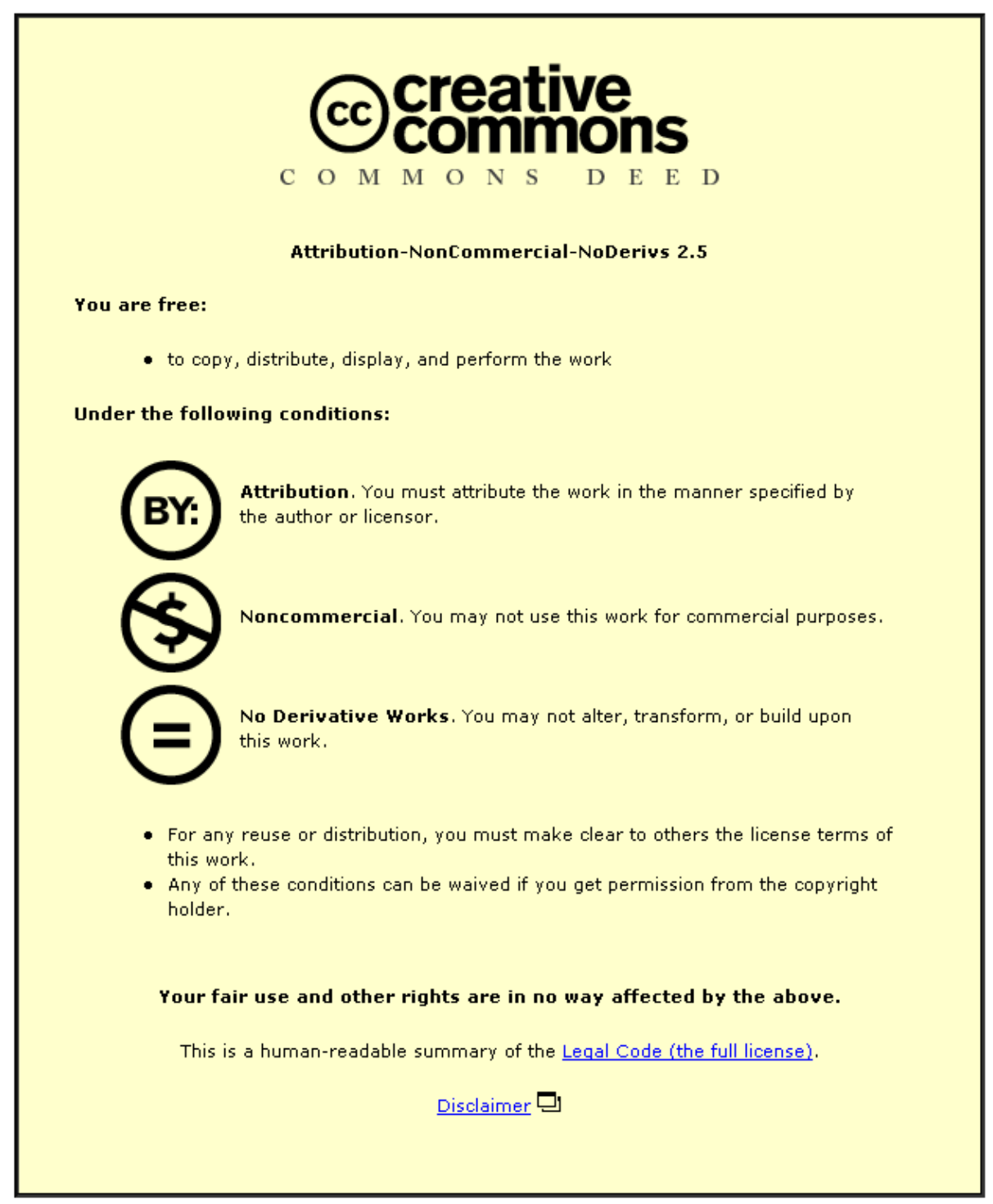

For the full text of this licence, please go to: http://creativecommons.org/licenses/by-nc-nd/2.5/ 
Using Dynamic Geometry to introduce Calculus concepts: CalGeo and the case of derivative Irene Biza and Theodossios Zachariades

Department of Mathematics, University of Athens (Greece)

Email:empiza@math.uoa.gr

Calculus has a wide field of applications in other disciplines and constitutes a basic part of the mathematical curriculum of secondary education. Nevertheless research shows that the majority of students face serious problems in understanding basic Calculus concepts (Artigue 1997).

The work presented in this paper originates in a three-year European funded project called CalGeo (Teaching Calculus Using Dynamic Geometric Tools). In this project a course for mathematics teachers was designed which employs dynamic geometry tools for teaching Calculus. Groups of in-service teachers in each of the participating countries (Greece, United Kingdom, Cyprus and Bulgaria) were trained in the course and then applied its materials and activities in their classrooms. For more information about the project see (Biza, Diakoumopoulos and Souyoul 2007) and the project website: www.math.uoa.gr/calgeo.

Parts of this project involve an activity designed for the introduction to the notion of derivative and some results of the application of this activity in a real classroom situation. For this introduction we use the tangent line as the limiting position of secant lines and as the linear approximation of the curve. Additionally, several cases of differentiable and non-differentiable functions are discussed through their geometrical and symbolic representations. In this application we employed a Dynamic Geometry software called EucliDraw with tools appropriate for Calculus instruction.

The implementation of the above activity in a Greek Year 12 classroom of 17 students raised issues - also known from the literature (e.g. Ferrara, Pratt and Robutti 2006) - such as: the student's adaptation in the unfamiliar classroom environment (e.g. regarding collaboration, communication, familiarity with electronic environments etc.), the effect of different representations and the role of examples in addressing student misconceptions etc.

On the basis of the above observations - very helpful for the development of the material of our project - the need for further and systematic research on the diverse situations that these environments create in the classroom community emerged.

The project was partially funded by the EU (grant 11892-CP-1-2004-1-GR-COMENIUS-C21).

\section{References}

Artigue, M. 1997. Teaching and learning elementary Analysis: What can we learn from didactical research and curriculum evolution? In Proceedings of 1st Mediterranean Conference on Mathematics, ed. by G. Makridis, 207-219. Nicosia, Cyprus.

Biza, I., D. Diakoumopoulos, and A. Souyoul. 2007, in press. Teaching analysis in dynamic geometry environments. Proceedings of the 5th Conference of European Research in Mathematics Education. Larnaca, Cyprus.

Ferrara, F., D. Pratt, and O. Robutti. 2006. The role and uses of technologies for the teaching of Algebra and Calculus. In Handbook of Research on the Psychology of Mathematics Education: Past, Present and Future, ed. A. Gutierrez and P. Boero, 237-273. Rotterdam, The Netherlands: Sense Publishers. 